\title{
Extrinsic and Common Coagulation Pathways in End-stage Renal Disease Associated with Spinal Cord Injury
}

\author{
N. D. Vaziri, M.D., R. L. Winer, M.D., S. Alikhani, J. Toohey, P. Paule, \\ K. Danviryasum, M.D., S. Gordon, M.D., I. Eltorai, M.D. \\ Division of Nephrology, Department of Medicine, University of California, Irvine \\ and SCI and Medical Services, Long Beach VA Medical Center, California, \\ U.S.A.
}

\section{Summary}

Data on the effects of combined long-standing spinal cord injury (SCI) and end-stage renal disease $(E S R D)$ on blood coagulation system are limited. We studied the extrinsic and common pathways of blood coagulation system in 9 men with SCIESRD treated with maintenance hemodialysis. Plasma procoagulant activities of factors (F)VII, $X$ and II were measured in a clotting assay using appropriate deficient plasmas as substrate. In addition, the antigen concentration of FII was measured using monospecific antibodies against human FII raised in goat in a gradient plate immunodiffusion system. Also measured were plasma fibrinogen concentration and platelet count. The results were compared with those obtained in a group of 10 ambulatory ESRD patients and 8 normal control volunteers. Plasma coagulant activity of FVII was markedly elevated and plasma fibrinogen concentration was moderately increased in SCI-ESRD patients. In contrast, plasma FII was mildly depressed while platelet count was within normal limits in SCI-ESRD patients. The data indicate that the combination of SCI and ESRD can lead to the alteration of the extrinsic and common coagulation pathways. Further studies are needed to elucidate the precise mechanism and the clinical significance of the observed abnormalities.

\section{Introduction}

A variety of coagulation and platelet abnormalities have been previously demonstrated in ambulatory patients requiring maintenance hemodialysis (Vaziri et al., 1984, Warrell et al., 1979, Jorgensen and Stoffersen, 1978). However, until recently no information was available on coagulation profile in spinal cord injured (SCI) patients with end-stage renal disease (ESRD). We have recently demonstrated marked antithrombin III deficiency and profound alteration of intrinsic coagulation pathway (Vaziri et al., 1985a, Vaziri et al., 1985b) in SCI-ESRD 
patients. The present study was intended to examine the remaining portion of the blood coagulation system.

\section{Patients, Materials and Methods}

Nine patients with combined SCI and ESRD were included in the study. They were all men (aged 36 to 62 years) with long-standing spinal cord injury which varied from C5 to L5 and 15 to 33 years in duration. Etiology of ESRD included chronic pyelonephritis, nephrolithiasis, amyloidosis and hypertensive nephrosclerosis. Duration of hemodialysis averaged 38 months ranging from 1 week to 93 months. Dialysis regimen consisted of 4-hour treatments thrice weekly. Single-PASS dialysate delivery system, glucose-free, acetate-based dialysate and hollow fiber cellulosic dialyzers were used. Porcine heparin was administered in 4 divided doses during dialysis to prevent clot formation in the extracorporeal circuit. Dietary restrictions included $\mathrm{H}_{2} \mathrm{O}, \mathrm{Na}$ and $\mathrm{K}$ intakes to control fluid overload and hyperkalemia. Aluminum carbonate was prescribed to control hyperphosphatemia and folic acid and multivitamins were given to prevent vitamin deficiencies.

Ambulatory ESRD group-Ten ambulatory ESRD men aged 31 to 85 years, maintained on hemodialysis for 5 to 45 months were included for comparison. The etiology of ESRD in this group included chronic glomerulonephritis in 4 patients, nephrosclerosis in 3 and polycystic kidney disease, diabetic nephropathy and ESRD of unknown cause each in one patient. Dialysis schedule, dietary and drug regimens in this group were comparable with those of the SCI group.

Normal control group-Eight normal volunteers aged 31 to 54 years served as the control group. They had normal prothrombin time (PT), partial thromboplastin time (PTT) and no history of coagulopathies, liver disease, nutritional deficiencies, renal or neurological disorders and did not receive medications known to affect coagulation system.

Materials-Deficient plasma substrates with less than $1 \%$ activity for factors VII (congenitally deficient human plasma), $\mathrm{X}$ (congenitally deficient human plasma), II (aged human serum and barium absorbed bovine plasma) were employed to measure the procoagulant activities of the respective factors. Monospecific antibody against human prothrombin (Factor II) raised in goat was employed in the measurement of plasma Factor II antigen concentration. A normal pooled plasma standard purchased from Dade Diagnostics, Inc. (Miami, Florida) was used as the internal standard for coagulation and immunological assays.

Methods-Blood samples for coagulation studies were obtained immediately before dialysis treatment at least 48 hours after the last heparinization associated with previous dialysis. Blood samples were drawn in plastic syringes and were collected in chilled plastic tubes containing sodium citrate (blood/citrate $=9 / 1$ volume). Plasma was rapidly separated by centrifugation at $4000 \mathrm{rpm}$ for 15 minutes and promptly frozen at $-70^{\circ} \mathrm{C}$ till assayed.

Procoagulant activities of each coagulation factor was measured using the respective factor deficient plasmas in appropriate clotting assays. Fibrinogen concentration was determined using a turbidometric method (Cannarzzi, et al., 1977). Factor II antigen concentration was measured using a monospecific 
antibody against human prothrombin in a gradient plate immunodiffusion system as previously described by our group (Ibsen et al., 1983, Vaziri et al., 1984 b).

The internal standard used was a normal pooled plasma obtained from many normal donors. All values are expressed as per cent of those found in the normal pooled plasma standard. A t-test was used in statistical analysis of the data which are shown as mean \pm SD.

\section{Results}

The results are summarized in the Table.

Factor VII-Factor VII procoagulant activity in the SCI-ESRD group was significantly greater than that found in the ambulatory-ESRD patients $(\mathrm{p}<$ $0.002)$ and the normal control group $(\mathrm{p}<0.001)$. Eight of the 9 SCI-ESRD patients showed values exceeding $100 \%$ while the remaining patient had a plasma factor VII activity of $100^{\circ}$.

Factor $X$-Plasma Factor X coagulant activity in the SCI-ESRD patients as a group was not significantly different from those found in the ambulatory-ESRD

Table The extrinsic and common coagulation pathways in SCI-ESRD patients maintained on hemodialysis as compared to ambulatory dialysis patients and a normal control group. Presented are coagulant activities of factors VII, X, II (act), and antigen concentration of factor II (Ag:conc), as ${ }^{\circ} \circ$ of those found in a pooled normal plasma standard. Prothrombin time (PT), partial thromboplastin time (PTT), fibrinogen $(\mathrm{Fbg})$ concentration and platelet (plt) count are also shown. The data are presented as mean (X) and standard deviation (S.D.) with $\mathrm{p}$ values less than 0.05 considered significant.

\begin{tabular}{|c|c|c|c|c|c|c|c|c|}
\hline \multicolumn{9}{|c|}{ SCI-Hemodialysis Patients (SCI-ESRD) } \\
\hline No. & $\begin{array}{l}\text { F VII } \\
(\text { act })\end{array}$ & $\begin{array}{l}\text { F X } \\
(\text { act })\end{array}$ & $\begin{array}{l}\text { F II } \\
(\text { act })\end{array}$ & $\begin{array}{c}\text { F II } \\
(\mathrm{Ag}: \text { conc })\end{array}$ & $\begin{array}{c}\mathrm{Fbg} \\
(\mathrm{mg} / \mathrm{dl})\end{array}$ & $\begin{array}{c}\text { PT } \\
(\mathrm{sec})\end{array}$ & $\begin{array}{l}\text { PTT } \\
(\mathrm{sec})\end{array}$ & $\begin{array}{c}\text { plt } \\
\left(\times 10^{3}\right)\end{array}$ \\
\hline 1 & 1000 & 275 & 100 & 100 & 275 & 10.7 & 22.1 & 297 \\
\hline 2 & 120 & 120 & 58 & 69 & 417 & $12 \cdot 4$ & $30 \cdot 9$ & 307 \\
\hline 3 & 1000 & 130 & 84 & 100 & 725 & $14 \cdot 5$ & $25 \cdot 0$ & 313 \\
\hline 4 & 100 & 85 & 62 & 98 & 290 & $10 \cdot 8$ & $25 \cdot 3$ & 167 \\
\hline 5 & 115 & 68 & 90 & 100 & 413 & $12 \cdot 0$ & $24 \cdot 6$ & 536 \\
\hline 6 & 190 & 120 & 80 & 100 & 311 & $11 \cdot 3$ & $26 \cdot 6$ & 387 \\
\hline 7 & 800 & 240 & 70 & 100 & 405 & $10 \cdot 5$ & $27 \cdot 0$ & 169 \\
\hline 8 & 120 & 105 & 69 & 49 & 259 & $12 \cdot 3$ & $27 \cdot 1$ & 248 \\
\hline 9 & 1000 & 170 & 125 & 100 & 177 & NA & NA & 149 \\
\hline $\mathrm{X}$ & 494 & 146 & 82 & 91 & 364 & $11 \cdot 8$ & $26 \cdot 1$ & 286 \\
\hline S.D. & 438 & 70 & 21 & 18 & 158 & $1 \cdot 3$ & $2 \cdot 5$ & 124 \\
\hline \multicolumn{9}{|c|}{ Ambulatory Hemodialysis Patients (AMB-ESRD) } \\
\hline $\mathrm{X}$ & 184 & 100 & 82 & 235 & 456 & $16 \cdot 6$ & $28 \cdot 3$ & 251 \\
\hline S.D. & 36 & 17 & 25 & 184 & 111 & $3 \cdot 6$ & $2 \cdot 3$ & 51 \\
\hline \multicolumn{9}{|c|}{ Control Group (NL-Controls) } \\
\hline $\mathrm{X}$ & 108 & 102 & 104 & 114 & 234 & $11 \cdot 6$ & $26 \cdot 9$ & 284 \\
\hline S.D. & 16 & 9 & 9 & 24 & 55 & $0 \cdot 7$ & $4 \cdot 0$ & 51 \\
\hline \multicolumn{9}{|c|}{$\begin{array}{l}P \text { values } \\
\text { SCI-ESRD vs. AMB-ESRD }\end{array}$} \\
\hline & $<0.002$ & NS & NS & $<0.05$ & NS & $<0.01$ & NS & NS \\
\hline \multicolumn{9}{|c|}{ SCI-ESRD vs. NL-Controls } \\
\hline & $<0.001$ & NS & $<0.05$ & $<0.05$ & $<0.05$ & NS & NS & NS \\
\hline \multicolumn{9}{|c|}{ AMB-ESRD vs. NL-Controls } \\
\hline & $<0.001$ & NS & $<0.02$ & NS & $<0.001$ & $<0.001$ & NS & NS \\
\hline
\end{tabular}


and the normal control groups. However, values exceeding $200 \%$ were found in two and values below $100 \%$ were found in two SCI-ESRD patients.

Factor II (prothrombin)-Plasma factor II activity in the SCI-ESRD group was comparable with that of the ambulatory-ESRD group. However, the values obtained in both ESRD groups were significantly lower than that found in the normal control group. Factor II antigen concentration in SCI-ESRD group was significantly $(\mathrm{p}<0.05)$ lower than those found in the ambulatory ESRD and normal control groups.

Fibrinogen-Plasma fibrinogen concentrations in both SCI-ESRD and ambulatory-ESRD groups were significantly greater than the corresponding value in the normal control group. Values exceeding $400 \mathrm{mg} / \mathrm{dl}$ were found in 4 of the 9 patients in the SCI group.

Platelet count-No significant differences were found in the platelet counts obtained in the three groups. None of the patients exhibited thrombocytopenia while one SCI-ESRD patient showed mild thrombocytosis.

\section{Discussion}

Plasma factor VII coagulant activity was markedly elevated in the SCI-ESRD patients and moderately increased in ambulatory-ESRD patients. The latter is in confirmation of our earlier findings in ambulatory-ESRD patients (Vaziri et al., 1984a). These observations suggest that ESRD and/or maintenance hemodialysis treatment somehow increase plasma factor VII level. However, greater magnitude of factor VII elevation in the SCI-ESRD group as compared to the ambulatory group is indicative of the additive effect of long-standing SCI and the associated conditions. The mechanism by which long-standing SCI contributes to this abnormality and its clinical significance is not known and requires further investigation.

According to our results, plasma factor $\mathrm{X}$ activity in the SCI-ESRD patients as a group is normal although moderate elevations may be seen in some patients.

Plasma factor II procoagulant activity and antigen concentration were mildly reduced in SCI-ESRD patients. However, this was not considered to be clinically significant since none of the patients showed factor II procoagulant activity below $50 \%$. Plasma fibrinogen concentration was mildly elevated in both SCI-ESRD and ambulatory ESRD patients and a mild thrombocytosis was found in one patient. Interestingly PT and PTT were within normal limits in all SCI patients despite several abnormalities of the individual clotting factors noted in the present study and those found in our earlier study of the intrinsic pathway (Vaziri et al., 1985b). This is probably due to the co-existence of opposing influences, i.e. increased coagulant activities of some factors (e.g. VII, VIII, fibrinogen) and decreased values of the others (e.g. factor II) in these patients. The former abnormalities would be expected to shorten and the latter to prolong PT and PTT. The combination of these abnormalities, therefore, can lead to little or no change in PT and PTT values which reflect the cumulative influences of several factors.

In conclusion, the present study has demonstrated a number of abnormalities in the extrinsic and common coagulation pathways in SCI-ESRD patients undergoing maintenance hemodialysis. In some instances clear differences existed between the ambulatory and SCI patients suggesting the possible 
pathogenetic role of long-standing SCI and/or its consequences. Some of these conditions include chronic urinary tract infection, osteomyelitis, pressure ulcers, amyloidosis and physical hypoactivity frequently present in SCI-ESRD patients and usually absent in the ambulatory group (Vaziri et al., 1984b). The clinical significance of the abnormalities shown in the present study is not known. Long-term clinical evaluations are required to determine the incidence of possible hemorrhagic or thromboembolic phenomena in this population.

\section{Acknowledgement}

The authors would like to thank Myra Fono for preparing the manuscript.

\section{Résumé}

Les taux plasmatiques des facteurs VII, X, II et de fibrinogène ont été déterminés chez 9 individus paralysés par suite de lésions médullaires et étant en insuffisance renale chronique traitée par hemodialyse. Les résultats sont comparés avec ceux obtenus d'une part chez 10 individus ambulants étant en insuffisance rénale chronique traitée par hémodialyse, et, d'autre part, chez 8 autres supposés normaux.

La population paralysée montre une augmentation tres̀ importante du facteur VII avec un taux de fibrinogène modérément élevé, un taux du facteur II légèrement réduit et un nombre de plaquettes sanguines dans les limites de la normale. Ces résultats montrent que l'association de paralysie et d'insuffisance rénale chronique est accompagnée d'anomalies très importantes de la coagulation sanguine.

\section{Zusammenfassung}

Des Plasmaspiegel für Faktor VII, X, II und Fibrinogen wurde in 9 Patienten mit Rückenmarkverletzungen und chronischem Nierenversagen bestimmt. Im Vergleich mit 10 ambulanten Dialyse Patenten und 8 Kontrollen, war bei Dialyse Patienten mit Rückenmarkverletzungen Faktor VII bedentend erhöht, Fibrinogen leicht erhöht, Factor II leicht reduziert, und Blutplättchem normal.

Diese Resultate zeigen dass chronisches Nierenversagen in Patienten mit Rückenmarkverletzungen mit abnormaler blutgerinnung verbunden ist.

\section{References}

CannarzZi DB, Wardlow SC, MCPherdan P 1977 An improved turbidometric method for plasma fibrinogen. American Journal of Medical Technology 43:211-215.

IbSEN KH, NGo JLT, SÁNDERS DA, VAZIRI ND, Hung EK 1983 Use of gradient plate immunodiffusion technique. Journal of Immunological Methods 56:381-387.

JORGENSEN KA, STOFFERSEN E 1978 Antithrombin III in uremia. Scandinavian Journal of Haematology 22:442-448.

Vaziri ND, Toohey J, Paule P, Hung E, Darwish R, Alikhani S, Barton CH 1984 Urinary excretion and deficiency of prothrombin in nephrotic syndrome. American Journal of Medicine 77:433-436.

Vaziri ND, Toohey J, Paule P, Alikhani S, Hung E 1984 Coagulation abnormalities in patients with end-stage disease treated with hemodialysis. International Journal of Artificial Organs 7:323-326.

VAZIRI ND 1984b Chronic hemodialysis in end-stage renal disease associated with paraplegia. International Journal of Artificial Organs 7:111-114.

Vaziri ND, Winer RL, Alikhani S, Danviryasup K, Toohey J, Hung E, Gordon S, Eltorai I, Paule P 1985a Antithrombin deficiency in end-stage renal disease associated with paraplegia. Effect of hemodialysis. Archives of Physical Medicine and Rehabilitation 66:307-309.

Vaziri ND, Winer RL, Toohey J, Danviryasup K, Alikhani S, Eltorai I, Gordon S, Paule $P$ 1985b Intrinsic coagulation pathway in end-stage renal disease associated with spinal cord injury. International Journal of Artificial Organs 9:155-159.

WARRELl RP, JR, HULTIN MB, Coller BS 1979 Increased factor VIII von Willebrand factor antigen and von Willebrand factor activity in renal failure. American Journal of Medicine 66:226-228. 